\title{
Slow and fast changes in transmural pulmonary artery pressure in obstructive sleep apnoea
}

\author{
O. Marrone, M.R. Bonsignore, S. Romano, G. Bonsignore
}

Slow and fast changes in transmural pulmonary artery pressure in obstructive sleep apnoea. O. Marrone, M.R. Bonsignore, S. Romano, G. Bonsignore. (C) ERS Journals Ltd 1994

ABSTRACT: Our purpose was to assess how pulmonary artery pressure changes in relation to hypoxia and oesophageal pressure during obstructive sleep apnoeas.

Transmural systolic pulmonary artery pressure (Pрa,sтM), oxyhaemoglobin saturation $\left(\mathrm{SaO}_{2}\right)$ and oesophageal pressure were analysed in two samples of consecutive obstructive apnoeas in each of four patients.

In the first samples (samples A; probably recorded during non-rapid eye movement (NREM) sleep), $\mathrm{SaO}_{2}$ swings were small and repetitive. In the second samples (samples B; probably recorded during rapid eye movement (REM) sleep), they were large and more variable. Oesophageal pressure oscillated similarly in the two groups of samples. In all cases, transmural systolic pulmonary artery pressure progressively increased throughout apnoeas, and subsequently decreased in the interapnoeic periods. However, both early and end-apnoeic transmural systolic pulmonary artery pressure, remained stable in samples A; whilst they progressively increased in samples B. Transmural systolic pulmonary artery pressure at the beginning of each apnoea was inversely correlated with $\mathrm{SaO}_{2}$ at the end of the preceding apnoea. These results suggest that transmural systolic pulmonary artery pressure is influenced by $\mathrm{SaO}_{2}$, but does not vary at the same speed as $\mathrm{SaO}_{2}$. In all cases, beat-by-beat analysis showed, as expected, that the lower the oesophageal pressure, the higher the transmural systolic pulmonary artery pressure however, at each oesophageal pressure level, transmural systolic pulmonary artery pressure was more variable and higher, in samples B.

In conclusion, transmural systolic pulmonary artery pressure in obstructive apnoeas shows rapid changes, which reflect oesophageal pressure variations, and slower changes, which are likely to be caused by $\mathrm{Sao}_{2}$.

Eur Respir J., 1994, 7, 2192-2198.
Istituto di Fisiopatologia Respiratoria del CNR, Palermo, Italy.

\section{Correspondence: O. Marrone}

Istituto di Fisiopatologia Respiratoria del CNR

Via Trabucco 180

90146 Palermo

Italy

Keywords: Hypoxic vasoconstriction Obstructive sleep apnoea

Pulmonary artery pressure

Received: April 51994

Accepted after revision August 161994

This work was supported by the Italian National Research Council (CNR). Targeted project "Prevention and Control of Disease Factors". Subproject "Control of Cardiovascular Disease".
Pulmonary circulation is profoundly affected by obstructive sleep apnoeas (OSA). Pulmonary artery pressure (Ppa) in OSA, as referenced to atmospheric pressure, shows wide variations during obstructed respiratory efforts and reaches the highest levels as ventilation is resumed [1-3]. Conversely, when Ppa is measured as referenced to intrathoracic pressure, i.e. as transmural pressure, its oscillations during occluded breaths are greatly blunted; a progressive increase in its values is observed throughout apnoea, followed by a decrease soon after ventilation is resumed, until the early portion of the following apnoea [4].

The pathogenesis of Ppa variations during OSA is not clear. The factors which have been proposed for the pathogenesis of Ppa changes in OSA are: changes in cardiac output $[3,5]$, the mechanical influences of intrathoracic pressure swings [6, 7], and hypoxia $[1,4,5,8]$.

Many studies have suggested that hypoxia developed during OSA may have an important influence on Ppa behaviour. In fact, Ppa during sleep increases more during room air breathing than during oxygen administration [5]; Ppa values during OSA are usually inversely correlated with arterial oxygen tension $\left(\mathrm{PaO}_{2}\right)$ or oxyhaemoglobin saturation $\left(\mathrm{SaO}_{2}\right)$ values $[1,4]$; and Ppa at apnoea termination increases as $\mathrm{SaO}_{2}$ decreases during repetitive airway occlusion trials in dogs [8]. However, when oxygen was administered to blunt $\mathrm{SaO}_{2}$ oscillations during OSA occurring in non rapid eye movement sleep (NREM) sleep, no significant effect was found on transmural Ppa oscillations within apnoeas [9].

The studies published, so far, concerning the effect of hypoxia on Ppa in OSA have been limited to the highest nocturnal Ppa value [5], the highest value after occlusion [8], or the values recorded only in NREM sleep, when the range of $\mathrm{SaO}_{2}$ oscillation is limited [9]. In our previous study [9], we hypothesized that although hypoxia may determine, if any, only a minor increase in Ppa within each apnoea, it could cause a sustained increase in Ppa in consecutive apnoeas, since the time course of the response of the pulmonary vessels 
Samples A
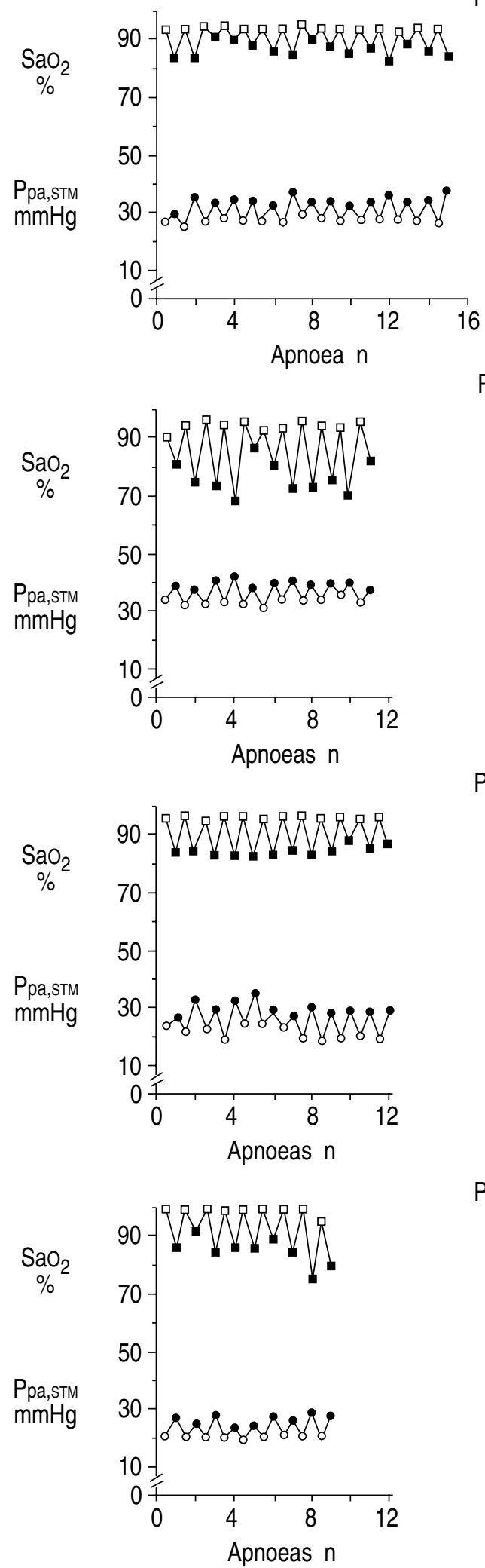

Pat No. 2

Samples B

Pat No. 1
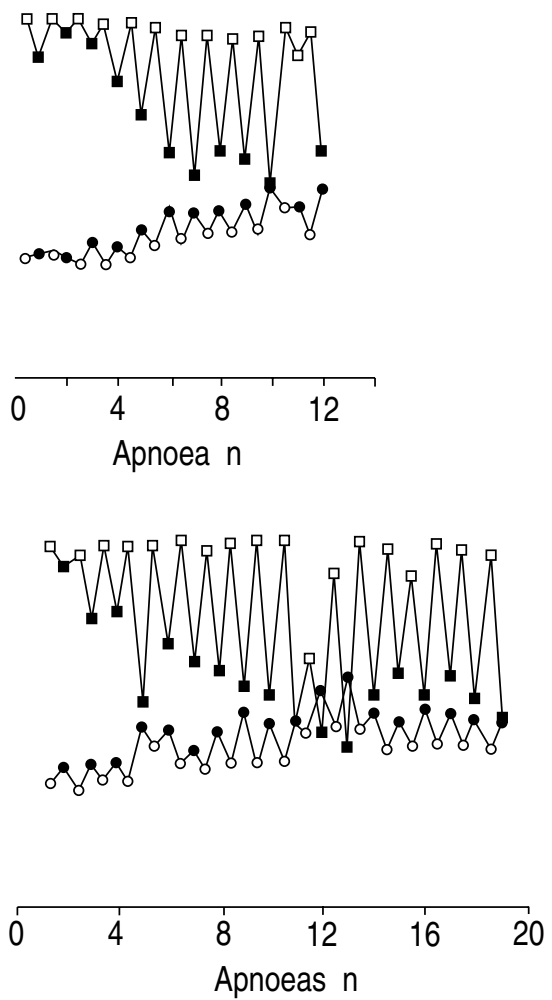

Pat No. 3
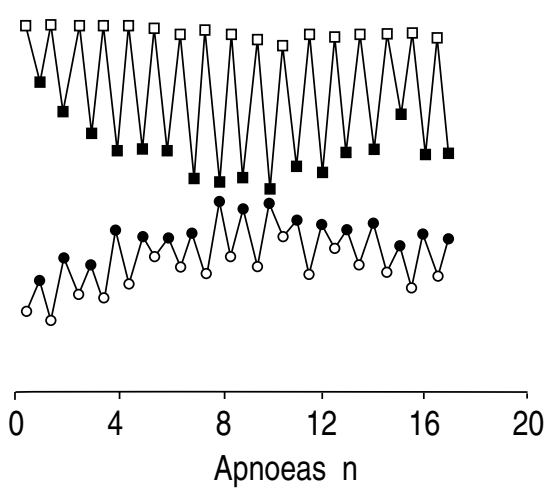

Pat No. 4

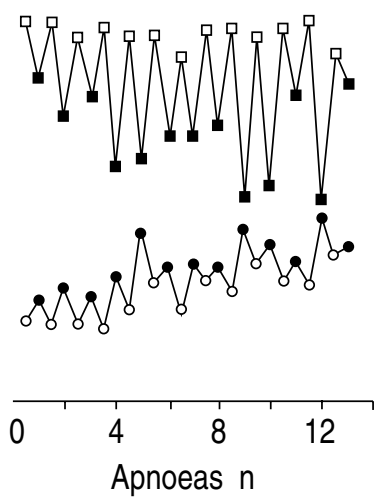

Fig. 1. - Consecutive values of $\mathrm{SaO}_{2}$ (upper part of each panel), and simultaneous values of Ppa,STM (lower part of each panel), in the sequences of apnoeic cycles of the A (left panels), and B (right panels) samples in each patient. Open symbols indicate beginning of apnoea $\left(\square \mathrm{SaO}_{2} \mathrm{~b}\right.$; $\bigcirc$ Ppa,STM,b), closed symbols indicate end of apnoea $\left(-\mathrm{SaO}_{2}\right.$ e, - Ppa,STM,e).Pat: patient; SaO ${ }_{2}$ : arterial oxygen saturation . Ppa,STM: transmural systolic pulmonary artery pressure; Samples A: apnoeas with small $\mathrm{SaO}_{2}$ falls; samples B: apnoeas with large $\mathrm{SaO}_{2}$ falls. 
to hypoxia may be slower than the $\mathrm{SaO}_{2}$ swings occurring in each apnoea episode. However, we could not prove this hypothesis, probably because of the interference, in our analysis, of intrathoracic pressure.

Therefore, to test our previous hypothesis, and to assess the influence of intrathoracic pressure swings on PPA measurements, we compared the variations in Ppa and $\mathrm{SaO}_{2}$ in spontaneously occurring consecutive obstructive apnoeic cycles, from samples which markedly differed in $\mathrm{SaO}_{2}$ falls, whilst monitoring oesophageal pressure (Poes).

\section{Patients and methods}

Four patients with a previously diagnosed OSA syndrome (mean apnoea index 75, range 52-91) underwent a nocturnal polysomnographic study with right heart catheterization. Patients were selected for this study if they showed a severe somnolence due to the OSA syndrome, so that they would be able to sleep with all the equipment necessary for the study. The study was approved by the scientific committee of our institution. Informed consent was given by all subjects. No complications were observed during the catheterizations.

The following signals were continuously recorded on an eight channel strip chart recorder (Hewlett-Packard $7758 \mathrm{~B}$ ) and stored on magnetic tape (Hewlett-Packard 3968 A): $\mathrm{SaO}_{2}$, by an Ohmeda Biox 3700 ear oximeter; oronasal flow; Poes, as an estimate of intrathoracic pressure, by a balloon-tipped catheter introduced in the lower third of the oesophagus, inflated with $1 \mathrm{ml}$ of air, and connected to a Validyne pressure transducer (MP 45-30-871); Ppa, in two subjects by a Swan-Ganz floating catheter connected to a Statham P 23 ID pressure transducer, and in the remaining two patients by a Millar catheter with tip transducer (Millar Instruments, model TC510). Electroencephalogram (EEG), electro-oculogram (EOG) and submental electromyogram (EMG) for the identification of NREM and rapid eye movement (REM) sleep, were monitored, on paper, in two subjects.

\section{Analysis}

As an apnoeic cycle, we considered a period including all the occluded breathing efforts of an apnoea, as well as the unoccluded breaths of the ventilatory period, which preceded another apnoea. In each patient, two uninterrupted sequences of 9-18 obstructive apnoeic cycles were selected for analysis. The first sequence, called sample A, included apnoeic cycles associated with relatively small $\mathrm{SaO}_{2}$ falls and little variability in $\mathrm{SaO}_{2}$ swings. The second sequence, called sample $\mathrm{B}$, included all the consecutive apnoeic cycles recorded during the night which were associated with marked $\mathrm{SaO}_{2}$ falls, as well as the three apnoeic cycles with small $\mathrm{SaO}_{2}$ swings preceding them; we included these three apnoeic cycles in samples $\mathrm{B}$ to analyse Ppa when the transition from relatively small into large $\mathrm{SaO}_{2}$ swings occurs (see fig. 1). Airflow, $\mathrm{SaO}_{2}$, Poes, and Ppa signals recorded in the selected apnoeic cycles were sampled at $5 \mathrm{~ms}$ intervals and, after analogue-to-digital conversion, stored in the mass memory of a computer (VAX 8200, Digital Equipment) and then analysed. Transmural Ppa values were obtained by computerized subtraction of Poes from intravascular Ppa.

Systolic transmural Рра (Рра,ьтм) was measured during 2 min of quiet breathing at the beginning of the studies as the mean \pm SD Pра,

To assess slow changes in Ppa in the apnoea sequences, Pра,sтм was measured as the lowest value at apnoea beginning (Ppa,sтм,b), and highest value at apnoea end or at the resumption of ventilation (Рpa,sтм,e). Both values were taken during late expiratory time, as indicated by a stable Poes level. These Ppa,sтм values were studied in relation to $\mathrm{SaO}_{2}$ levels, considered as highest $\mathrm{SaO}_{2}$ at the beginning $\left(\mathrm{SaO}_{2} \mathrm{~b}\right)$ and lowest $\mathrm{SaO}_{2}$ at the end of apnoeas $\left(\mathrm{SaO}_{2} \mathrm{e}\right)$.

To assess fast changes in Ppa within each apnoeic cycle, beat-by-beat Ppa,sтм was taken into account. All the measured Pра, ттм values were plotted against the Poes value in the immediately preceding end-diastolic time. Then, the Poes range from +5 to $-20 \mathrm{mmHg}$ was divided into $5 \mathrm{mmHg}$ intervals ( +5 to 0,0 to $-5,-10$ to $-5,-15$ to -10 , and -20 to $-15 \mathrm{mmHg}$ ). The variance of Ppa,sтм for each Poes interval was compared for each patient between samples A and B. Group mean values of Ppa,sтм in each Poes interval in samples A and B were also compared.

\section{Statistical analysis}

Data are given as mean \pm SD. Linear regression analysis was applied to study the relationship between $\mathrm{SaO}_{2}$ and Ppa,sтм. Variance ratio test was performed to compare variances of Pра,sтм values between samples A and $B$ for each Poes interval. Means were compared by twotailed t-test, unpaired or paired as appropriate. A $\mathrm{p}<0.05$ was considered significant.

\section{Results}

Characteristics of the patients and their Pра,sтм whilst awake are shown in table 1.

In each patient, apnoeas were always separated by short ventilatory intervals. Apnoeas in samples B were longer, and were characterized by similar or less pronounced Poes excursions than in samples A. Differences in $\mathrm{SaO}_{2} \mathrm{~b}$ between apnoeas in the two samples, although always significant, were small; whereas $\mathrm{SaO}_{2} \mathrm{e}$ was always much lower in samples B (table 2).

In samples $\mathrm{A}$, as $\mathrm{SaO}_{2}$ showed monotonous and relatively small swings, both Pра,sтмb and Pра,sтм,e values tended to remain constant in the consecutive apnoeic cycles. In samples $\mathrm{B}$, as $\mathrm{SaO}_{2}$ falls became greater, both Ppa,sтм, $\mathrm{b}$ and Рра,sтм,е showed a trend to a progressive increase; after the transition from small to large $\mathrm{SaO}_{2}$ swings, as large $\mathrm{SaO}_{2}$ swings recurred, both Pра,sтм,b and Pра,sтм,e remained at higher levels than in the A samples (fig. 1).

In all patients, when we pooled sample $\mathrm{A}$ and $\mathrm{B}$, Pра, мтм,b was highly and significantly linearly correlated with $\mathrm{SaO}_{2} \mathrm{e}$ in the preceding apnoea (fig. 2). 
Table 1. - Characteristics of the patients

\begin{tabular}{|c|c|c|c|c|}
\hline $\begin{array}{l}\text { Pat } \\
\text { No. }\end{array}$ & $\begin{array}{l}\text { Age } \\
\text { yrs }\end{array}$ & $\begin{array}{c}\mathrm{BMI} \\
\mathrm{kg} \cdot \mathrm{m}^{-2}\end{array}$ & $\begin{array}{c}\text { Awake } \mathrm{SaO}_{2} \\
\%\end{array}$ & $\begin{array}{c}\text { Initial } \\
\text { Ppa,STM,b } \\
\text { mmHg }\end{array}$ \\
\hline $1 \mathrm{~F}$ & 61 & 35.1 & 94 & $31.6 \pm 2.6$ \\
\hline $2 \mathrm{M}$ & 49 & 45.9 & 94 & $32.5 \pm 2.4$ \\
\hline $3 \mathrm{M}$ & 45 & 32.3 & 96 & $22.5 \pm 2.1$ \\
\hline $4 \mathrm{M}$ & 60 & 33.5 & 98 & $18.6 \pm 1.7$ \\
\hline
\end{tabular}

Pat: patient; F: female; M: male; BMI: body mass index; $\mathrm{SaO}_{2}$ : arterial oxygen saturation; Ppa,sтм: systolic transmural pulmonary artery pressure.
Beat-by-beat analysis showed, in all cases, that Ppa,sтм was higher when preceded by a more negative Poes (fig. 3 ); therefore, the highest Ppa,sтм values were recorded during the inspiratory efforts preceding the interapnoeic breaths, where the most negative Poes values are found. However, in samples B, at each Poes level Ppa,sтм values were more variable than in samples A (fig. 3); in fact the variance of Рра,sтм was significantly greater in samples B ( $\mathrm{p}$ always $<0.001)$ at every Poes interval. In addition, the group mean of Pра,sтм for every Poes interval was always significantly higher in samples B (fig. 4).
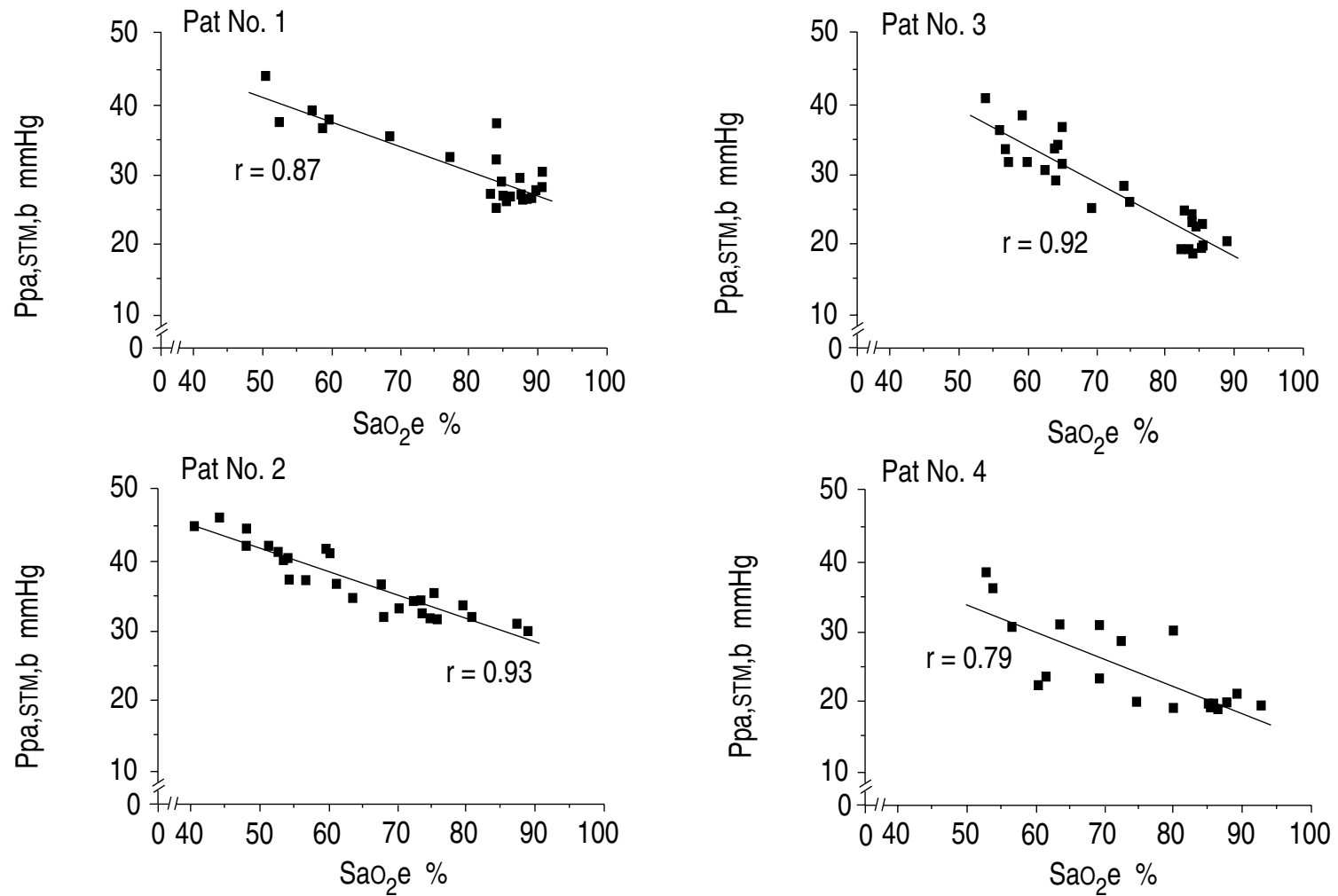

Fig. 2. - For each patient, correlations of Ppa,STM,b with $\mathrm{SaO}_{2} \mathrm{e}$ of the preceding apnoeic cycle. Apnoeic cycles of both samples A and B have not been separated for this analysis. For abbreviations see legend to figure 1.

Table 2. - Characteristics of the selected apnoeas

\begin{tabular}{|c|c|c|c|c|c|c|c|}
\hline $\begin{array}{l}\text { Pat } \\
\text { No. }\end{array}$ & Sample & $\begin{array}{c}\text { Apnoeas } \\
\mathrm{n}\end{array}$ & $\begin{array}{l}\text { Apnoea } \\
\text { duration } \mathrm{s}\end{array}$ & $\begin{array}{l}\text { Interapnoeic } \\
\text { duration } \mathrm{s}\end{array}$ & $\begin{array}{c}\text { Lowest Poes } \\
\text { mmHg }\end{array}$ & $\begin{array}{c}\mathrm{SaO}_{2} \mathrm{~b} \\
\%\end{array}$ & $\begin{array}{c}\mathrm{SaO}_{2} \mathrm{e} \\
\%\end{array}$ \\
\hline 1 & $\begin{array}{l}\text { A } \\
\text { B }\end{array}$ & $\begin{array}{l}15 \\
12\end{array}$ & $\begin{array}{l}20.3 \pm 4.3 \\
32.5 \pm 14.2 *\end{array}$ & $\begin{array}{l}14.3 \pm 4.8 \\
12.4 \pm 4.3\end{array}$ & $\begin{array}{l}-20.3 \pm 4.7 \\
-17.8 \pm 3.7\end{array}$ & $\begin{array}{l}93.8 \pm 0.7 \\
91.5 \pm 1.8 \dagger\end{array}$ & $\begin{array}{l}87.0 \pm 3.4 \\
69.2 \pm 14.7 * * * *\end{array}$ \\
\hline 2 & $\begin{array}{l}\mathrm{A} \\
\mathrm{B}\end{array}$ & $\begin{array}{l}11 \\
18\end{array}$ & $\begin{array}{l}23.5 \pm 5.6 \\
35.9 \pm 15.4 * *\end{array}$ & $\begin{array}{l}14.1 \pm 4.0 \\
11.9 \pm 5.2\end{array}$ & $\begin{array}{l}-39.6 \pm 8.4 \\
-32.1 \pm 7.1 * *\end{array}$ & $\begin{array}{l}94.1 \pm 8.4 \\
90.7 \pm 7.2\end{array}$ & $\begin{array}{l}76.1 \pm 5.7 \\
58.6 \pm 12.1 \dagger\end{array}$ \\
\hline 3 & $\begin{array}{l}\text { A } \\
\text { B }\end{array}$ & $\begin{array}{l}12 \\
17\end{array}$ & $\begin{array}{l}31.3 \pm 2.8 \\
47.3 \pm 9.2 \dagger\end{array}$ & $\begin{array}{l}18.6 \pm 2.6 \\
12.3 \pm 2.1 \dagger\end{array}$ & $\begin{array}{l}-33.4 \pm 4.8 \\
-32.9 \pm 6.2\end{array}$ & $\begin{array}{l}96.4 \pm 0.3 \\
94.8 \pm 1.5^{* * *}\end{array}$ & $\begin{array}{l}85.6 \pm 3.1 \\
62.4 \pm 6.0 \dagger\end{array}$ \\
\hline 4 & $\begin{array}{l}\mathrm{A} \\
\mathrm{B}\end{array}$ & $\begin{array}{r}9 \\
13\end{array}$ & $\begin{array}{l}42.5 \pm 8.8 \\
44.9 \pm 15.5\end{array}$ & $\begin{array}{l}13.6 \pm 2.5 \\
13.7 \pm 2.9\end{array}$ & $\begin{array}{l}-36.5 \pm 9.1 \\
-34.7 \pm 7.2\end{array}$ & $\begin{array}{l}98.9 \pm 1.4 \\
96.1 \pm 2.8 * *\end{array}$ & $\begin{array}{l}85.0 \pm 5.1 \\
67.5 \pm 10.3 \dagger\end{array}$ \\
\hline
\end{tabular}

Data are presented as mean \pm SD. Sample A: apnoes with small $\mathrm{SaO}_{2}$ falls; sample B: apnoes with large $\mathrm{SaO}_{2}$ falls. Pat: patient; Poes: oesophageal pressure; $\mathrm{SaO}_{2} \mathrm{~b}$ : arterial oxygen saturation at beginning of apnoea; $\mathrm{SaO}_{2} \mathrm{e}$ : arterial oxygen saturation at end of apnoea; $*, * * * * *, \dagger: \mathrm{p}<0.05,0.02,0.002,0.001$ respectively, A vs B. 

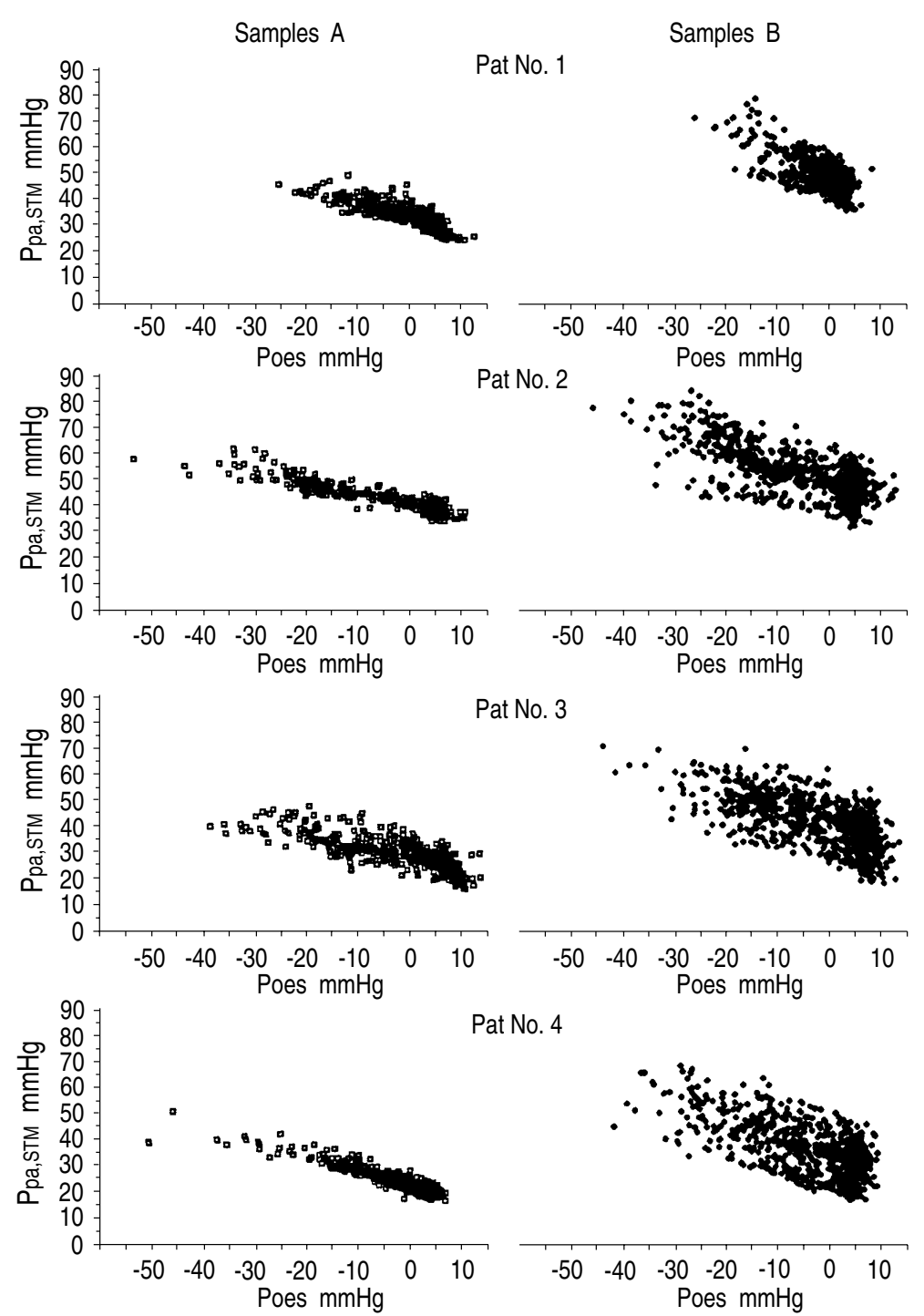

Fig. 3. - Beat-by-beat transmural systolic pulmonary artery pressure (Ppa,STM) measurements in the whole apnoeic cycles plotted against the immediately preceding end-diastole Poes in each subject. Poes: oesophageal pressure; Pat: patient.

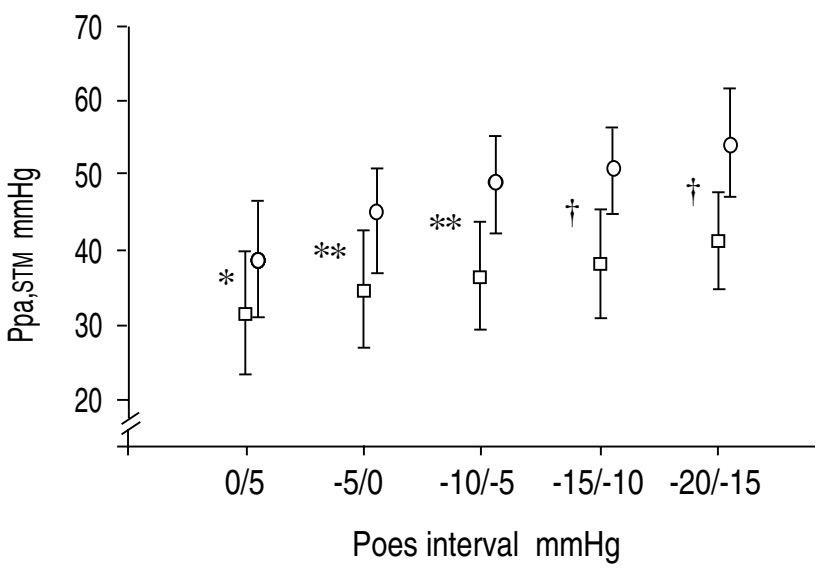

Fig. 4. - Group mean \pm sD for all patients of Ppa,sTM recorded at different Poes intervals in samples A $(\square)$ and B (O). Levels of significance of differences between the two samples are shown as: *: $\mathrm{p}<0.01 ; * *: \mathrm{p}<0.005 ; \uparrow: \mathrm{p}<0.002$. For abbreviations see legend to figure 3.

\section{Discussion}

In this study, we analysed the lowest and highest Ppa,sтм and $\mathrm{SaO}_{2}$ values in each of several consecutive apnoeic cycles, so as to investigate whether the time course of Ppa variations differed from the time course of $\mathrm{SaO}_{2}$ swings (fig. 1). We also measured Pра, sтм beat-by-beat to assess the rapid Ppa changes occurring in each apnoeic cycle.

Our main findings were twofold: a) obstructive apnoeas are associated with Ppa changes which are related to hypoxia but are not as rapid as $\mathrm{SaO}_{2}$ changes; in fact, $\mathrm{SaO}_{2}$ after each interapnoeic period $\left(\mathrm{SaO}_{2} \mathrm{~b}\right.$ tended to return to a substantially constant value, whatever the extent of its drop in each apnoea, whilst Pра,sтм was not reverted to a constant level after the largest increases (fig. 1); and b) transmural Ppa undergoes rapid changes, which reflect the changes in Poes (fig. 3): within each breath, either occluded or unoccluded, Pра,sтм was higher during the inspiratory time, when Poes falls, and was lower during the expiratory time, when Poes increases. 
When examining the slow changes in Рpa,sтм, i.e. those between the two extremities of apnoeic cycles, we took into account only expiratory Рра, ттм values, in order to minimize possible effects of intrathoracic pressure on our measurements. By using this approach, we observed that, as long as $\mathrm{SaO}_{2}$ swings were relatively small and monotonous, Pра,sтм,b and Ppa,sтм,e remained substantially constant; conversely, as $\mathrm{SaO}_{2}$ swings became more pronounced, due to greater $\mathrm{SaO}_{2}$ drops at the end of apnoeas, Ppa,sтм progressively increased, both in the levels recorded at the beginning and at the end of apnoeic cycles. In addition, we found that Pра,Sтм in the early portion of each apnoea was closely correlated with $\mathrm{SaO}_{2}$ at the end of the preceding one.

In the two subjects in whom EEG, EOG and EMG were monitored, we verified that the apnoeic cycles in samples A were recorded during NREM, and those in samples B during REM sleep; this probably also occurred in the remaining two subjects. A contribution of influences linked to NREM or REM sleep state to the Ppa behaviour in obstructive apnoeic cycles cannot be ruled out, but we are not aware of any study concerning a difference in the hypoxic pulmonary vessels response between NREM and REM sleep. However, our findings may be explained on the basis of the well-known time course of the pulmonary vessels response to hypoxia, which is slower than $\mathrm{SaO}_{2}$ changes during apnoeic cycles. In fact, hypoxic pulmonary vessel response starts within a few seconds of exposure to hypoxia but peaks only after some minutes [10-14]. $\mathrm{SaO}_{2}$ falls during sleep apnoeas are generally produced in less than a minute, and are reverted in only a few seconds. Therefore, the increase in Ppa from the beginning to the end of obstructive apnoeic cycles may not represent a full response to the level of hypoxia reached during apnoeas, but only part of the response that would occur if the same level of hypoxia were maintained for a longer time. Moreover, when hypoxia is relieved during the interapnoeic ventilatory interval, Ppa may not return to its baseline level, particularly when $\mathrm{SaO}_{2}$ falls markedly during apnoeas, because the relief of hypoxia is of too short a duration.

In addition, as suggested by PoDszus and co-workers $[6,7]$, hypoxia, in association with hypercapnia, could lead to a prolonged Ppa increase as a result of an insufficient interapnoeic ventilation.

Eventually, the effect of hypoxia could also derive from the repeated hypoxic challenges in the closely recurring OSA episodes. In fact, some authors have found an increase in the hypoxic pulmonary vasoconstriction with repeated intermittent hypoxia $[15,16]$. However, this finding has not been universal, and could be secondary to the experimental procedure [17].

In both $\mathrm{A}$ and $\mathrm{B}$ apnoea samples, the analysis of beat-by-beat Ppa,sтм showed that transmural Ppa closely follows Poes, so that the more negative the immediately preceding Poes, the higher Ppa,sтм along the entire range of Poes. However, at every Poes level, Ppa,sтm was higher and more variable in B than in A samples. These findings suggest that, as a result of the previously described influence of $\mathrm{SaO}_{2}$ on Ppa,sтм, at each Poes level Pра, стм progressively increased in consecutive ap- noeic cycles of the B samples, whilst the effect of Poes on Pра,sтм measurements remained unmodified; this explains the higher Ppa,sтм variance in the B samples. In addition, the relationship between Poes and Ppa,sтм measurements helps explain why transmural Ppa measurements, at variance from the intravascular ones, may sometimes be higher at apnoea end, when Poes excursions are marked, than immediately after apnoea [4].

The possibility for Ppa to increase progressively during the night had been pointed out in early studies [2, 3, 5]. However, in those papers, Ppa trend had not been studied in detail or correlated with the changes in $\mathrm{SaO}_{2}$. Our data suggest that a trend to a progressive increase in Ppa during repetitive apnoeas occurs and becomes evident only when the pattern of $\mathrm{SaO}_{2}$ behaviour changes from small to large swings.

The design of this study does not allow for a clear recognition of the role of intrathoracic pressure on transmural Ppa. In fact, we could not compute a regression beween Poes and Ppa,sтм, since Poes during systole, which is very close to end-diastole Poes, is included in the calculation of Ppa,sтм, and we would have obtained a spurious correlation.

However, other studies have demonstrated that negative intrathoracic pressure increases transmural Ppa [1820]. Such an increase could be consequent to an increase in right ventricular preload [21] and output [21, 22], or to an increase in left ventricular afterload [18-20, 23]. However, PoDszus and co-workers [6] considered negative intrathoracic pressure as a possible cause for a decrease, and not for an increase, in Ppa, due to possible extrathoracic vein collapse and venous return limitation; in fact, venous return was found to be limited by extrathoracic vein collapse when threshold negative intrathoracic pressure levels were exceeded [24]. As concerns left ventricular afterload, its increase was regarded as the possible cause for an increase in pulmonary wedge pressure recorded in OSA, which, in turn, could determine an increase in Ppa [25]. Conversely, in a canine experimental model, no difference was found between the left ventricular systolic pressure recorded in the inspiratory and in the expiratory time during periodic upper airway obstruction [26]; which is not consistent with an increase in afterload during the inspiratory effort. In fact, the afterloading effect of negative intrathoracic pressure on the left ventricle is controversial, and could be evident only when intrathoracic pressure reaches very negative levels [27]. In OSA patients, echocardiographic evaluation of right and left ventricular volume, performed while monitoring Poes, demonstrated that both ventricular volumes change during each obstructed breath of OSA; as documented by Poes, the right ventricle reaches the largest size, and the left ventricle the lowest size, during the inspiratory effort, whilst the opposite occurs at the release of the inspiratory effort [28].

Our data may thus suggest that there is an effect of intrathoracic pressure on Ppa, but other data in the literature more strongly support that effect. Whatever the mechanism by which negative intrathoracic pressure may act, the results of most studies on this subject support our view that the decrease in intrathoracic pressure may cause an increase in transmural Ppa. 
A possible role for an increase in cardiac output at the release of obstruction as a cause of the postapnoeic increase of Ppa, as previously suggested $[3,5]$, can no longer be upheld, in the light of the recent studies which have shown a decrease in cardiac output in the immediate post-apnoeic period [29, 30].

In conclusion, in this study we have found that transmural Ppa in obstructive apnoeic cycles shows two types of oscillation: a) rapid changes, which are synchronous with Poes changes and can be detected in each breath, either occluded or unoccluded; and b) slower changes, consisting of an increase from the beginning to the end of the apnoeic cycle, and a decrease from the end of the apnoeic cycle to the beginning of the following one. We believe that hypoxia is a major determinant of the slower transmural Ppa changes in OSA. However, pulmonary vessels are not able to fully respond to the ra-pid $\mathrm{SaO}_{2}$ changes occurring during apnoeas. Thus, the variation in Ppa in the apnoeic cycle may include only an incomplete response to the level of $\mathrm{SaO}_{2}$ that is reached either at its beginning or at its end, whilst some effects of hypoxia may still be present beyond the time of the apnoea where it is produced, in the following apnoeic cycle.

\section{References}

1. Coccagna G, Mantovani M, Brignani F, Parchi C, Lugaresi E. Continuous recording of the pulmonary and systemic arterial pressure during sleep in syndromes of hypersomnia with periodic breathing. Bull Physiopathol Respir 1972; 8: $1159-1172$

2. Lonsdorfer J, Meunier-Carus J, Lampert-Benignus E, et al. Aspects hemodinamiques et respiratoires du syndrome Pickwickien. Bull Physiopathol Respir 1972; 8: 1181-1192.

3. Tilkian A, Guilleminault C, Schroeder JS, Lehrman KL, Simmons FB, Dement WC. Hemodynamics in sleepinduced apnea: studies during wakefulness and sleep. Ann Intern Med 1976; 85: 714-719.

4. Marrone O, Bellia V, Ferrara G, et al. Transmural pressure measurements. Importance in the assessment of pulmonary hypertension in obstructive sleep apneas. Chest 1989; 95: 338-342.

5. Schroeder JS, Motta J, Guilleminault C. Hemodynamic studies in sleep apneas. In: Guilleminault C, Dement WC, eds. Sleep apnea syndromes. New York, AR Liss Inc., 1978; 13: pp. 1146-1162.

6. Podszus T, Mayer J, Penzel T, Peter JH, von Wichert P. Nocturnal hemodynamics in patients with sleep apnea. Eur J Respir Dis 1986; 69 (Suppl. 146): 435-442.

7. Podszus T, Greenberg H, Scharf SM. Influence of sleep state and sleep-disordered breathing on cardiovascular function. In: Saunders NA, Sullivan CE, eds. Sleep and Breathing. New York, M. Dekker Inc., 1994; pp. 257-310.

8. Iwase N, Kikuchi Y, Hida W. Effects of repetitive airway obstruction on $\mathrm{O}_{2}$ saturation and systemic and pulmonary arterial pressure in anesthetized dogs. Am Rev Respir Dis 1992; 145: 1402-1410.

9. Marrone O, Bellia V, Pieri D, Salvaggio A, Bonsignore G. Acute effects of oxygen administration on transmural pulmonary artery pressure in obstructive sleep apnea. Chest 1992; 101: 1023-1027.

10. Malik AB, Kidd BSL. Time course of pulmonary artery response to hypoxia in dogs. Am J Physiol 1973; 224; 1-6.

11. Ohe M, Mimata T, Haneda T, Takishima T. Time course of pulmonary vasoconstriction with repeated hypoxia and glucose depletion. Respir Physiol 1986; 63: 177-186.

12. Thompson BT, Hassoun PM, Kradin RL, Hales CA. Acute and chronic hypoxic pulmonary hypertension in guinea-pigs. J Appl Physiol 1989; 66: 920-928.

13. Jensen KS, Micco AJ, Czartolomna J, Latham L, Voelkel F. Rapid onset of hypoxic vasoconstriction in isolated lungs. J Appl Physiol 1992; 72: 2018-2023.

14. Welling KLK, Sanchez R, Ravn JB, Larsen B, Amtorp O. Effect of prolonged alveolar hypoxia on pulmonary arterial pressure and segmental vascular resistance. $J$ Appl Physiol 1993; 75: 1194-1200.

15. Unger M, Atkins M, Briscoe WA, King TKC. Potentiation of pulmonary vasoconstrictor response with repeated intermittent hypoxia. J Appl Physiol Respirat Environ Exercise Physiol 1977; 43: 662-667.

16. Benumof J. Intermittent hypoxia increases lobar hypoxic pulmonary vasoconstriction. Anesthesiology 1983; 58: 399_ 404.

17. Chen L, Miller FL, Williams JJ, et al. Hypoxic pulmonary vasoconstriction is not potentiated by repeated intermittent hypoxia in closed chest dogs. Anesthesiology 1985; 63: 608-610.

18. Schrijen F, Ehrlich W, Permutt S. Cardiovascular changes in conscious dogs during spontaneous deep breaths. Pflügers Arch 1975; 355: 205-215.

19. Robotham JL, Lixfeld W, Holland L, MacGregor D, Bryan AC, Rabson J. Effects of respiration on cardiac performance. J Appl Physiol: Respirat Exercise Physiol 1978; 44: 703-709.

20. Scharf SM, Brown R, Saunders N, Green LH. Effects of normal and loaded spontaneous inspiration on cardiovascular function. $J$ Appl Physiol: Respirat Environ Exercise Physiol 1979; 47: 582-590.

21. Blaustein AS, Risser TA, Weiss JW, Parker JA, Holman L, McFadden ER. Mechanisms of pulsus paradoxus during resistive respiratory loading and asthma. $J \mathrm{Am}$ Coll Cardiol 1986; 8: 529-536.

22. Andreas S, Werner GS, Sold G, Wiegand V, Kreuzer H. Doppler echocardiographic analysis of cardiac flow during the Mueller manoeuvre. Eur J Clin Invest 1991; 21: 72-76.

23. Scharf SM, Brown R, Tow DE, Parisi AF. Cardiac effects of increased lung volume and decreased pleural pressure in man. J Appl Physiol: Respirat Environ Exercise Physiol 1979; 47: 257-262.

24. Guyton AC, Lindsey AW, Abernathy B, Richardson T. Venous return at various right atrial pressures and the normal venous curve return. Am J Physiol 1957; 189: 609-615.

25. Buda AJ, Schroeder JS, Guilleminault C. Abnormalities of pulmonary artery wedge pressures in sleep-induced apnea. Int J Cardiol 1981; 1: 67-74.

26. Scharf SM, Graver LM, Balaban K. Cardiovascular effects of periodic occlusions of the upper airway in dogs. Am Rev Respir Dis 1992; 146: 321-329.

27. Scharf SM. Cardiovascular effects of airway obstruction. Lung 1991; 169: 1-23.

28. Shiomi T, Guilleminault C, Stoohs R, Schnittger I. Leftward shift of the intraventricular septum and pulsus paradoxus in obstructive sleep apnea syndrome. Chest 1991; 100: 894-902.

29. Garpestad E, Katayama H, Parker JA, et al. Stroke volume and cardiac output decrease at termination of obstructive apneas. J Appl Physiol 1992: 73: 1743-1748

30. Bonsignore MR, Marrone O, Romano S, Pieri D. Time course of right ventricular stroke volume and output in obstructive sleep apneas. Am J Respir Crit Care Med 1994; 149: 155-159. 